\title{
ALK NP_004295.2:p.I1170N
}

National Cancer Institute

\section{Source}

National Cancer Institute. ALK NP 004295.2:p.11170N. NCI Thesaurus. Code C133478.

A change in the amino acid residue at position 1170 in the ALK tyrosine kinase receptor protein where isoleucine has been replaced by asparagine. 